\title{
Glutathione S-transferase pi polymorphism contributes to the treatment outcomes of advanced non-small cell lung cancer patients in a Chinese population
}

\author{
J.B. Chen, F. Wang, J.J. Wu and M. Cai \\ Department of Radiotherapy, \\ Peace Hospital Attached to Changzhi Medical College, Changzhi, Shanxi, China \\ Corresponding author: J.B. Chen \\ E-mail: jianbc21@126.com \\ Genet. Mol. Res. 15 (3): gmr.15037498 \\ Received August 21, 2015 \\ Accepted December 29, 2015 \\ Published July 25, 2016 \\ DOI http://dx.doi.org/10.4238/gmr.15037498
}

Copyright $(92016$ The Authors. This is an open-access article distributed under the terms of the Creative Commons Attribution ShareAlike (CC BY-SA) 4.0 License.

\begin{abstract}
We analyzed the association between polymorphisms in three glutathione S-transferase genes (GSTP1, GSTM1, and GSTT1) and the treatment outcome for advanced non-small cell lung cancer (NSCLC). We recruited 284 NSCLC patients at advanced stage from Department of Radiotherapy in Peace Hospital Attached to Changzhi Medical College between May 2009 and May 2011, who had received cisplatin-based chemotherapy. The GSTP1, GSTM1, and GSTT1 genotyping for was determined using DNA pyrosequencing on an ABI Prism 3100 DNA analyzer. In the Cox proportional hazards model, the IIe/Val and Val/Val genotypes of GSTP1 were associated with lower risk of disease progression compared with the IIe/IIe genotype, and the HRs $(95 \%$ CIs $)$ were $0.37(0.18-0.74)$ and $0.15(0.06-0.35)$, respectively. The IIe/Val and Val/Val genotypes
\end{abstract}


significantly decreased risk of death from all causes in patients with NSCLC, and the HRs (95\%CIs) were 0.52 (0.29-0.92) and 0.37 (0.17$0.79)$, respectively No significant association was observed between GSTM1 and GSTT1 polymorphisms and progression-free survival and overall survival in the NSCLC patients. In summary, we suggest that GSTP1 polymorphisms might influence the treatment outcome of advanced NSCLC patients, and our results could help improve individualized therapy.

Key words: GSTP1; GSTM1; GSTT1; Polymorphism; NSCLC

\section{INTRODUCTION}

Lung cancer was the most prevalent and lethal form of cancer in both men and women in 2012 worldwide (IARC, 2012). It is estimated that over a million people are affected by lung cancer globally each year (IARC, 2012). In 2012, lung cancer was the first cause of death among people with malignant tumors in China (Ferlay et al., 2010). Nonsmall cell lung cancer (NSCLC) is the most common type of lung cancer. Although both individual and combination treatments, such as surgery, radiotherapy, and chemotherapy, have improved the survival of patients with NSCLC in recent years, long-term survival could still be improved. The TNM classification system is the basis for the prognostic management of NSCLC; however, it does not provide sufficient information about biological tumor progression (Chansky et al., 2009). There is still demand for biomarkers that can predict patient survival.

GSTP1, GSTM1, and GSTT1 are three members of the human glutathione S-transferases (GSTs) super family of genes, and they are polymorphic in humans. Previous studies have reported that GST polymorphisms can influence the effectiveness of the detoxification of cytotoxins generated by cisplatin-based chemotherapy in several kinds of cancer, including osteosarcoma, cervical cancer, and gastric cancer (Daukantienè et al., 2014; Yu et al., 2014; Goričar et al., 2015). The authors of several studies have investigated the relationship between GST polymorphisms and the prognosis of NSCLC, but the results are inconsistent. Therefore, we conducted a study to examine the association between GSTP1, GSTM1, and GSTT1 polymorphisms and treatment outcomes for advanced NSCLC in a Chinese population.

\section{MATERIAL AND METHODS}

\section{Patients}

We recruited 284 NSCLC patients at advanced stage from department of radiotherapy in Peace Hospital Attached to Changzhi Medical College between May 2009 and May 2011, who had received cisplatin-based chemotherapy. All the patients were pathologically confirmed as being at stage IIIA, IIIB, or IV. The exclusion criteria for patients with advanced NSCLC were those that had not previously underwent any systemic anticancer therapies prior to enrollment, and had severe complications, acute and chronic infection diseases, liver and renal dysfunctions, and/or organ failure and brain metastasis, were excluded from this study.

Genetics and Molecular Research 15 (3): gmr.15037498 


\section{Assessment of treatment outcome}

After enrollment into this study, advanced NSCLC patients underwent cisplatin-based combination chemotherapy. The advanced NSCLC patients received physical examination and computed tomography scan before cisplatin-based combination chemotherapy. The patients received cisplatin-based combination chemotherapy for at least four cycles unless there was unacceptable toxicity or disease progression to continue treatment. Chemotherapy response was evaluated based on the Response Evaluation Criteria in Solid Tumors (RECIST 1.1) using computed tomography scan examination. Progression-free survival (PFS) and overall survival (OS) were used as the endpoints. PFS was calculated from the date of chemotherapy to the data of confirmed progression, death from any cause or the end of follow-up. OS was calculated from the date of chemotherapy to the data of death from any cause or the end of follow-up. Patients were followed-up by return visits and telephone conversations, and patients were followed-up at the end of May 2014. Up to May 2014, patients were followed-up for 2-60 months, with a median follow-up time of 24.35 months. A total of 271 cases were followed-up, while 13 cases were lost to follow-up.

\section{DNA extraction and genotyping}

Each subject was asked to provide a peripheral blood sample $(2 \mathrm{~mL})$ and the samples were stored at $-20^{\circ} \mathrm{C}$ until required. Genomic DNA was extracted from peripheral blood lymphocytes using a QIAamp DNA Blood Mini Kit (Qiagen, Hilden, Germany) according to the manufacturer instructions. The GSTP1, GSTM1, and GSTT1 genotyping for was determined using DNA pyrosequencing on an ABI Prism 3100 DNA analyzer (Applied Biosystems, USA). The forward and reverse primer sequences for GSTP1 were 5'-GAA GAG CCA AGG ACA GGT CC-3' and 5'-CAA CTT CAT CCA CGT TCA AC-3', respectively; those for GSTM1 were 5'-CTG GGG TAC TTG ATT GAT CCC-3' and 5'-CTG GAT TGT AGC AGA TCA TGC-3'; and those for GSTT1 were 5'-TTC CTT ACT GGT CCT CAC ATC CC-3' and 5'-TCA GGC GAT CAT GGC CAG AC-3'; those for $\beta$-globin were 5'-GAA GAG CCA AGG ACA GGT CC-3' and 5'-CAA CTT CAT CCA CGT TCAAC-3'. The length of digested fragment for GSTP1, GSTM1, GSTT1 and $\beta$-globin were 215, 480, 176 and 286 bp, respectively.

\section{Statistical analysis}

The demographic and clinical characteristics of patients with advanced NSCLC were expressed by frequencies and percentages. The associations between GSTP1, GSTM1, and GSTT1 polymorphisms and PFS and OS were testing the hazard ratios (HRs) and 95\% confidence intervals ( $95 \% \mathrm{CIs}$ ) from multivariate Cox proportional hazards regression analysis, and the common genotypes of GSTP1, GSTM1, and GSTT1 were used as reference group. Data were subjected to statistical SPSS Statistics software (version 19.0, SPSS Inc., Chicago, IL, USA), and two-sided $\mathrm{P}$ values $<0.05$ was considered the threshold for statistically significance.

\section{RESULTS}

The demographic and clinical information of the advanced NSCLC patients are described in Table 1. The advanced NSCLC is composed of 97 females and 187 males, and

Genetics and Molecular Research 15 (3): gmr.15037498 
their mean age was $63.60 \pm 11.65$ years. In the NSCLC patients, 171 patients smoked tobacco, 39 had a family history of cancer, 134 had squamous carcinoma, 150 had adenocarcinoma, 216 were at TNM stages IIIA or IIIB, 68 were at TNM stage IV, 127 had NSCLC located in the left lung, and 146 had NSCLC located in the right lung.

Table 1. Demographic and clinical information of the non-small cell lung cancer (NSCLC) patients.

\begin{tabular}{l|c|c}
\hline Parameter & Patients & $\%$ \\
\hline Age, years & & 57.04 \\
\hline$<60$ & 162 & 42.96 \\
\hline$\geq 60$ & 122 & 34.15 \\
\hline Gender & 97 & 65.85 \\
\hline Female & 187 & 39.79 \\
\hline Male & & \\
\hline Tobacco consumption & 113 & 60.21 \\
\hline Never & 171 & 86.27 \\
\hline Sometimes & & 13.73 \\
\hline Family history of cancer & 245 & 47.18 \\
\hline No & 39 & 52.82 \\
\hline Yes & & \\
\hline Histological types & 134 & 76.06 \\
\hline Squamous carcinoma & 150 & 23.94 \\
\hline Adenocarcinoma & & \\
\hline TNM stage & 216 & 44.72 \\
\hline IIIA and IIIB & 68 & 51.41 \\
\hline IV & & \\
\hline Location & 127 & 3.87 \\
\hline Left & 146 & \\
\hline Right & 11 & \\
\hline Other & & \\
\hline
\end{tabular}

Up to the end of follow-up, 206 patients showed progression, and 78 showed nonprogression. After adjustment for clinical variables, the IIe/Val and $\mathrm{Val} / \mathrm{Val}$ genotypes of GSTP1 had a shorter PFS time compared with the IIe/IIe genotype (for IIe/Val vs IIe/IIe, 21.65 vs 16.60 months; for Val/Val vs IIe/IIe, 22.52 vs 16.60 months). In the Cox proportional hazards model, the IIe/Val and Val/Val genotypes of GSTP1 were associated with lower risk of disease progression compared with the IIe/IIe genotype, and the HRs (95\% CIs) were 0.37 (0.18-0.74) and 0.15 (0.06-0.35), respectively (Table 2). However, no significant association was found between GSTM1 and GSTT1 polymorphisms and PFS in NSCLC.

Table 2. Association between GSTP1, GSTM1, and GSTT1 polymorphisms and progression-free survival (PFS) innon-small cell lung cancer (NSCLC).

\begin{tabular}{l|c|c|c|c|c|c|c|c}
\hline Genotypes & Patients & $\%$ & Progression & $\%$ & Non-progression & $\%$ & HR (95\%CI $)^{1}$ & P value \\
\hline GSTM1 & & & & & & & & \\
\hline Present & 162 & 57.2 & 121 & 58.74 & 41 & 62.86 & 1.0 (Ref.) & - \\
\hline Null & 122 & 42.8 & 85 & 41.26 & 37 & 37.14 & $0.78(0.45-1.36)$ & 0.35 \\
\hline GSTT1 & & & & & & & & \\
\hline Present & 155 & 54.5 & 118 & 57.28 & 37 & 53.33 & 1.0 (Ref.) & - \\
\hline Null & 129 & 45.5 & 88 & 42.72 & 41 & 46.67 & $0.67(0.39-1.17)$ & 0.14 \\
\hline GSTP1 & & & & & & & & - \\
\hline IIe/IIe & 115 & 40.6 & 99 & 48.06 & 16 & 33.33 & 1.0 (Ref.) & - \\
\hline IIe/Val & 121 & 42.6 & 84 & 40.78 & 37 & 35.24 & $0.37(0.18-0.74)$ & 0.002 \\
\hline Val/Val & 48 & 16.8 & 23 & 11.17 & 25 & 32.38 & $0.15(0.06-0.35)$ & $<0.001$ \\
\hline
\end{tabular}

${ }^{1}$ Adjusted for age, gender, and TNM stage.

Up to May 2014, a total of 173 patients with NSCLC died from all causes, and the 5-year overall survival rate was $39.08 \%$. The IIe/Val and Val/Val genotypes of GSTP1 were

Genetics and Molecular Research 15 (3): gmr.15037498 
associated with longer overall survival of NSCLC compared with the IIe/IIe genotype (for IIe/ Val vs IIe/IIe, 25.32 vs 21.85 months; for Val/Val vs IIe/IIe, 27.40 vs 21.85 months). In the Cox proportional hazards model, the IIe/Val and Val/Val genotypes significantly decreased risk of death from all causes in patients with NSCLC, and the HRs (95\%CIs) were $0.52(0.29-0.92)$ and 0.37 (0.17-0.79), respectively (Table 3 ). No significant association was observed between GSTM1 and GSTT1 polymorphisms and OS in NSCLC.

\begin{tabular}{|c|c|c|c|c|c|c|c|c|}
\hline Genotypes & Patients & $\%$ & Death & $\%$ & Alive & $\%$ & HR $(95 \% \mathrm{CI})^{1}$ & $\mathrm{P}$ value \\
\hline \multicolumn{9}{|l|}{ GSTM1 } \\
\hline Present & 162 & 57.2 & 102 & 58.96 & 60 & 54.05 & 1.0 (Ref.) & - \\
\hline Null & 122 & 42.8 & 71 & 41.04 & 51 & 45.95 & $0.82(0.49-1.36)$ & 0.42 \\
\hline \multicolumn{9}{|l|}{ GSTT1 } \\
\hline Present & 155 & 54.5 & 98 & 56.65 & 57 & 51.35 & 1.0 (Ref.) & - \\
\hline Null & 129 & 45.5 & 75 & 43.35 & 54 & 48.65 & $0.81(0.49-1.34)$ & 0.38 \\
\hline \multicolumn{9}{|l|}{ GSTP1 } \\
\hline $\mathrm{IIe} / \mathrm{IIe}$ & 115 & 40.6 & 82 & 47.40 & 33 & 29.73 & 1.0 (Ref.) & - \\
\hline IIe/Val & 121 & 42.6 & 68 & 39.31 & 53 & 47.75 & $0.52(0.29-0.92)$ & 0.02 \\
\hline $\mathrm{Val} / \mathrm{Val}$ & 48 & 16.8 & 23 & 13.29 & 25 & 22.52 & $0.37(0.17-0.79)$ & 0.005 \\
\hline
\end{tabular}

Adjusted for age, gender, and TNM stage.

\section{DISCUSSION}

Increasing evidence has indicated that the genetic variations of drug-metabolizing enzymes, drug transporters, and drug targets involve in the inter-individual differences in the treatment efficacy of chemotherapy for cancers. In this study, we evaluated whether the GSTP1, GSTM1, and GSTT1 polymorphisms could have an impact on the treatment outcomes for NSCLC in a Chinese population. We revealed that the IIe/Val and Val/Val genotypes were associated with a lower risk of disease progression and death from all causes compared to the IIe/IIe genotype. No significant association was found between GSTM1 and GSTT1 polymorphisms and progression and survival in NSCLC.

GST enzymes were reported to have a crucial role in metabolizing many xenobiotics and cytotoxic cancer chemotherapeutic agents (Tew et al., 1996). Previous study reported that GSTP1 is the most abundant isoenzyme among GSTs and is over-expressed in cancer or precancerous tissues (Tiseo et al., 2013). Genetic variation of GSTP1 could result in amino acid substitution changes of GSTP 1 and cause to hydroliphobicity of amino acids, which could contribute to the enzymatic stability and catalytic capability.

Currently, many studies have investigated the relationship between GSTP1 genetic polymorphism and treatment outcome of chemotherapy in several kinds of cancer, such as bone tumors, colorectal cancer, breast cancer and gastric cancer (Jun et al., 2009; Li et al., 2010; Romero et al., 2012; Yang et al., 2012; Eralp et al., 2013; Ye et al., 2013). Jun et al. (2009) conducted a study with 122 advanced colorectal cancer patients, and reported that the $\mathrm{Val} /$ Val genotype of GSTP1 is correlated with a higher clinical response to chemotherapy and with better survival of patients. Li et al. (2010) conducted a study in a Chinese population and reported that Val allele had better prognosis and response to oxaliplatin regimen for patients with advanced gastric cancer. Romero et al. (2012) carried out a study in Spanish population and reported that varied expression of GSTP1 contributes to the clinical outcome of breast cancer. Yang et al. (2012) conducted a study with 187 patients with osteosarcoma, and

Genetics and Molecular Research 15 (3): gmr.15037498 
indicated that GSTP1 genetic polymorphism might play a role in the response to chemotherapy and prognosis of bone tumors. Eralp et al. conducted a study in a Turkish population, and indicated that downregulation of GSTP1 could improve progression-free survival in advanced breast cancer patients (Eralp et al., 2013). The results of these studies reported that GSTP1 polymorphisms affect chemotherapy sensitivity and the prognosis for several kinds of cancers.

Many studies have reported the relationship between GSTP1 polymorphisms and prognosis of advanced NSCLC, but the results are inconclusive (Booton et al., 2006; Lu et al., 2006; Vlachogeorgos et al., 2008; Kalikaki et al., 2009; Sun et al., 2010; Lv et al., 2014; Han et al., 2015). Sun et al. (2010), Han et al. (2015) and Lv et al., (2014) conducted studies in Chinese populations and reported that GSTP1 genetic variations might be the predictive markers for the treatment outcome of advanced NSCLC. Booton et al. (2006), Vlachogeorgos et al. (2008) and Lu et al. (2006) carried out studies in Caucasians and they reported that GSTP1 polymorphisms may predict response to treatment and survival in patients with advanced NSCLC. However, Kalikaki et al. (2009) did not revealed a significant correlation between GSTP1 genetic polymorphisms and treatment outcomes in advanced NSCLC. The inconsistency in these studies may be attributed to the discrepancies in ethnicity, selection of patients, and sample size.

In summary, we suggest that GSTP1 polymorphisms might influence the treatment outcome of advanced NSCLC patients, and our results could help improve individualized therapy.

\section{Conflicts of interest}

The authors declare no conflict of interest.

\section{ACKNOWLEDGMENTS}

We thanks for the great help from staffs in Peace Hospital Attached to Changzhi Medical College.

\section{REFERENCES}

Booton R, Ward T, Heighway J, Ashcroft L, et al. (2006). Glutathione-S-transferase P1 isoenzyme polymorphisms, platinum-based chemotherapy, and non-small cell lung cancer. J. Thorac. Oncol. 1: 679-683.

Chansky K, Sculier JP, Crowley JJ, Giroux D, et al.; International Staging Committee and Participating Institutions (2009). The International Association for the Study of Lung Cancer Staging Project: prognostic factors and pathologic TNM stage in surgically managed non-small cell lung cancer. J. Thorac. Oncol. 4: 792-801. http://dx.doi.org/10.1097/ JTO.0b013e3181a7716e

Daukantienė L, Kazbarienė B, Valuckas KP, Didžiapetrienė J, et al. (2014). The significance of reduced glutathione and glutathione S-transferase during chemoradiotherapy of locally advanced cervical cancer. Medicina (Kaunas) 50: 222-229. http://dx.doi.org/10.1016/j.medici.2014.09.005

Eralp Y, Keskin S, Akışık E, Akışık E, et al. (2013). Predictive role of midtreatment changes in survivin, GSTP1, and topoisomerase $2 \alpha$ expressions for pathologic complete response to neoadjuvant chemotherapy in patients with locally advanced breast cancer. Am. J. Clin. Oncol. 36: 215-223. http://dx.doi.org/10.1097/COC.0b013e318243913f

Ferlay J, Shin HR, Bray F, Forman D, et al. (2010). Estimates of worldwide burden of cancer in 2008: GLOBOCAN 2008. Int. J. Cancer 127: 2893-2917. http://dx.doi.org/10.1002/ijc.25516

Goričar K, Kovač V, Jazbec J, Zakotnik B, et al. (2015). Genetic variability of DNA repair mechanisms and glutathioneS-transferase genes influences treatment outcome in osteosarcoma. Cancer Epidemiol. 39: 182-188. http://dx.doi. org/10.1016/j.canep.2014.12.009

Genetics and Molecular Research 15 (3): gmr.15037498 
Han B, Guo Z, Ma Y, Kang S, et al. (2015). Association of GSTP1 and XRCC1 gene polymorphisms with clinical outcome of advanced non-small cell lung cancer patients with cisplatin-based chemotherapy. Int. J. Clin. Exp. Pathol. 8: 4113-4119.

International Agency for Research on Cancer (IARC) (2012). Lung Cancer. Estimated Incidence, Mortality and Prevalence Worldwide in 2012. Available at [http://globocan.iarc.fr/Pages/fact_sheets_cancer.aspx?cancer=lung]. Accessed October 22, 2015.

Jun L, Haiping Z and Beibei Y (2009). Genetic polymorphisms of GSTP1 related to response to 5-FU-oxaliplatin-based chemotherapy and clinical outcome in advanced colorectal cancer patients. Swiss Med. Wkly. 139: 724-728.

Kalikaki A, Kanaki M, Vassalou H, Souglakos J, et al. (2009). DNA repair gene polymorphisms predict favorable clinical outcome in advanced non-small-cell lung cancer. Clin. Lung Cancer 10: 118-123. http://dx.doi.org/10.3816/ CLC.2009.n.015

Li QF, Yao RY, Liu KW, Lv HY, et al. (2010). Genetic polymorphism of GSTP1: prediction of clinical outcome to oxaliplatin/5-FU-based chemotherapy in advanced gastric cancer. J. Korean Med. Sci. 25: 846-852. http://dx.doi. org/10.3346/jkms.2010.25.6.846

Lu C, Spitz MR, Zhao H, Dong Q, et al. (2006). Association between glutathione S-transferase pi polymorphisms and survival in patients with advanced nonsmall cell lung carcinoma. Cancer 106: 441-447. http://dx.doi.org/10.1002/ cncr.21619

Lv H, Han T, Shi X, Yao Y, et al. (2014). Genetic polymorphism of GSTP1 and ERCC1 correlated with response to platinum-based chemotherapy in non-small cell lung cancer. Med. Oncol. 31: 86. http://dx.doi.org/10.1007/s12032014-0086-5

Romero A, Martín M, Oliva B, de la Torre J, et al. (2012). Glutathione S-transferase P1 c.313A > G polymorphism could be useful in the prediction of doxorubicin response in breast cancer patients. Ann. Oncol. 23: 1750-1756. http:// dx.doi.org/10.1093/annonc/mdr483

Sun N, Sun X, Chen B, Cheng H, et al. (2010). MRP2 and GSTP1 polymorphisms and chemotherapy response in advanced non-small cell lung cancer. Cancer Chemother. Pharmacol. 65: 437-446. http://dx.doi.org/10.1007/s00280-009$\underline{1046-1}$

Tew KD, Monks A, Barone L, Rosser D, et al. (1996). Glutathione-associated enzymes in the human cell lines of the national cancer institute drug screening program. Mol. Pharmacol. 50: 149-159.

Tiseo M, Bordi P, Bortesi B, Boni L, et al.; Bio-FAST trial group (2013). ERCC1/BRCA1 expression and gene polymorphisms as prognostic and predictive factors in advanced NSCLC treated with or without cisplatin. $B r . J$. Cancer 108: 1695-1703. http://dx.doi.org/10.1038/bjc.2013.127

Vlachogeorgos GS, Manali ED, Blana E, Legaki S, et al. (2008). Placental isoform glutathione S-transferase and P-glycoprotein expression in advanced nonsmall cell lung cancer: association with response to treatment and survival. Cancer 114: 519-526. http://dx.doi.org/10.1002/cncr.23981

Yang LM, Li XH and Bao CF (2012). Glutathione S-transferase P1 and DNA polymorphisms influence response to chemotherapy and prognosis of bone tumors. Asian Pac. J. Cancer Prev. 13: 5883-5886. http://dx.doi.org/10.7314/ APJCP.2012.13.11.5883

Ye F, Liu Z, Tan A, Liao M, et al. (2013). XRCC1 and GSTP1 polymorphisms and prognosis of oxaliplatin-based chemotherapy in colorectal cancer: a meta-analysis. Cancer Chemother. Pharmacol. 71: 733-740. http://dx.doi. org/10.1007/s00280-012-2067-8

Yu P, Du Y, Yang L, Fan S, et al. (2014). Significance of multidrug resistance gene-related proteins in the postoperative chemotherapy of gastric cancer. Int. J. Clin. Exp. Pathol. 7: 7945-7950.

Genetics and Molecular Research 15 (3): gmr.15037498 